\title{
Port Site Recurrences Following Laparoscopic Liver Resection for Hepatocellular Carcinoma: Reply
}

\section{Robert Martin ${ }^{1}$}

Published online: 7 April 2016

(C) Société Internationale de Chirurgie 2016

To the Editor,

Thank you very much for your kind comments in response to our manuscript outlining the outcomes of laparoscopic liver resection in comparison to open liver resection for hepatocellular cancer.

We thoroughly understand the concern for port site recurrence, which has been an ongoing concern as far back as the initiation of laparoscopic colectomy for colon cancer nearly 15 years ago.

In a review of our data we have actually seen two patients who developed a port site recurrence at the $5 \mathrm{~mm}$ port site not at the location of specimen extraction. It should be emphasized that all laparoscopic liver extraction should be removed in some form of large tear proof extraction bag so that spillage of even small microscopic cells can be avoided. With these results of two out of 100 patients who developed a port site recurrence, we still do believe that laparoscopic liver resection has significant advantages over open liver resections in the appropriate patient, the appropriate sized tumor, and the appropriate location of tumor.

Port site, biopsy site, and incision site recurrences will always be a concern in patients who undergo resections for Hepato-Pancreatico-Biliary malignancies. However, most commonly the biology of these diseases is such that port site recurrences are exceedingly rare and in many instances usually coincide with far more extensive recurrences within the peritoneum, lung, and other solid organ.

Robert Martin

robert.martin@louisville.edu

1 Division of Surgical Oncology, Department of Surgery, University of Louisville, Louisville, USA 